\title{
Research on the Connotation and Mode of Computer Training Base Built by China and Russia Jointly
}

\author{
Liang Yu \\ Heihe University \\ Heihe, Heilongjiang, China 164300
}

\begin{abstract}
With the rapid development of the computer technology, the computer specialty has been set up successively like mushrooms after rain in domestic universities. Heilongjiang has geographical advantage because it is located in the border of China and Russia. Training base plays a decisive role in the applied specialties of higher education. This paper has analyzed and researched the education condition of computer in Chinese universities and Russia, introducing the significance in setting up the training base, the connotation construction of training base and the mode of training base construction.
\end{abstract} mode

Keywords-computer education; training base; connotation;

\section{INTRODUCTION}

The computer was applied in the military initially. Russia researches the computer very early, with strong software capability. The computer specialty in Russia is popular among overseas students. In recent years, the computer has developed rapidly in China both in software and hardware. It has distinctly important significance for China and Russia to jointly establish the training base through analyzing the meaning of computer education reform in Russia and referring to the methods used by Russia in researching the computer education.

\section{ThE CURRENT SituAtion OF EDUCATION IN RUSSIA}

\section{A. The Process of Educational Reform in Russia}

Russia has begun the basic education reform since the twentieth century. The most important part is the course reform, mainly adjusting the objective training and teaching contents. The education curriculum standards of Russia mainly include three aspects: "the national standard of Russian Federation, the regional standard of Russia and the standard of educational institutions". The national curriculum standards of general education have stipulated the overall standard, ability, skill and activity method in each stage respectively. The provisions of new curriculum standard have many changes and the formulation of standard is distinctive. Teaching contents are set and suitable for the rule of students' physical and mental healthy development according to different characteristics in different stages. It can greatly ease the learning burden of students; the courses require the integrated development of students, including the comprehensive improvement in grasping knowledge, ability development, comprehensive breeding and practical ability. Requirements are set according to the changes of social development, which strengthen the humanities of teaching contents. In order to efficiently implement of new standard of curriculum provision, Russia has carried out the supporting reforms like the teaching materials reform. However, difficulties exist in the effective implementation of courses in Russia and require a prompt solution.

\section{B. The Reform and Development of Computer Education}

At present, Russia has passed the federal program about informatization of the educational field in the computer education. Computer classroom and computer network environment should be set in different educational institutions of Russia. The Russian government will invest plenty of capitals to update the computer technology and reform the hardware equipment. Meanwhile, the training and teaching center of basic computer knowledge should be built by different federal subjects. The educational institutions of computer conform to the measures of basic curriculum reform in Russia.

The computer specialty is popular in universities of Russia. The computer specialty of the Saint Petersburg State Polytechnical University and the computer department of Saint Petersburg Optical Machinery Institute are the most famous in Russia, ranking the third and the fifth among the international computer universities respectively. The curriculum provision of the computer specialty in Russia is advanced and reaches the first level in the world. The employment status of students graduated from the computer specialty in Russia is optimistic and they are provided with fat salary.

\section{THE DEVELOPMENT AND CURRENT SiTUATION OF COMPUTER EDUCATION IN CHINA}

Although the computer education in China starts late, after years of construction, the education of computer specialty in our country has made great progress. The computer specialty has been provided in many universities. However, with the rapid development of the computer specialty, many problems still exist in the Chinese computer education. With the development of IT industry and the popularization of computer and network application, the requirements for talents in the computer application also increases, creating opportunities for schools to train talents of the computer specialty. Nevertheless, the operational capacity and the comprehensive quality of 
students are poor. The specialty hasn't been detailed. It is necessary to explore the reform of teaching methods, letting students grasp the basic theory as well as the basic operation of computer, from the blind learning to the conformity to the requirements of the society and the posts, from the duckstuffing learning to the active learning.

\section{REFERENCE OF THE TEACHING REFORM EXPERIENCE IN RUSSIA}

The educational reform of basic courses in Russia starts early. The computer basic courses develop fast. It has the world first class level in the software development. In the reform process, the advantages include the overall popularization of the computer education and the allocation of the computer network and the hardware facilities. The diversified education like the combination of learning with working, the computer with the military is adopted in the educational process. However, defects also exist in the computer education of Russia, such as the low coverage of supporting policies and the low implementation efficiency, worthy of our reflection. Therefore, the computer education reform in our country should base on the government support, take students as the main body and adhere to the combination of learning with working under the guidance of projects. With the advantaged geographical location, Heilongjiang is more proper to exchange the computer education experience with Russia and reform the computer courses to make it more advanced and suitable for learning.

\section{Significance in Building the Training BaSE JOINTLY}

The training base plays a distinctly important role in training the applied talents in local colleges. It is built in accordance with the objective of talents training in universities, in order to train students' ability in applying the professional technology and their occupational qualities. With respect to the training base built by China and Russia jointly, it can refer to the professional teaching and talent training mode in universities at home and abroad and combine with local characteristics and the reality on campus. Except for finishing the necessary experiment and practical training, students can expand their horizon in the training base outside school and have a deeper understanding for the specialty. The training base can enrich the contents of practical teaching and improve the practical ability of students; the education of vocational quality on students in the training can stimulate their learning enthusiasm and improve the social adaptation ability, letting students adapt to the practical work faster after graduation.

\section{ConNotation CONSTRUCtion OF THE TRAining BASE}

The connotation of training base refers to the feelings of people for the existing equipment, management, environment and the mental state of people in the training base. The connotation construction is the construction of intrinsic essential attributes. The intrinsic attributes of training base include the organization structure and management system. The purpose of connotation construction of the training base is to improve the soft power, shape the brand image and improve the quality and efficiency.

\section{A. Necessity of the Connotation Construction}

The construction of training base is the important guarantee to realize the objective of talents training. The improvement of connotation of the training base is the requirements of selfdevelopment. It is the policy requirement of the higher education development to strengthen the training base construction. The Ministry of Education states it is necessary to reform the traditional teaching methods centering on the school and the classroom, pay attention to the practical teaching, the project teaching and the team learning; open diversified courses to improve students' enthusiasm in learning; strengthen the education of vocational quality like honesty and trustworthiness and dedication to work, reinforce the training of students' employment and entrepreneurial ability as well as the innovation consciousness, in order to promote the college students to become talents.

\section{B. Significance of the Connotation Construction}

The construction of training base helps to train the comprehensive professional quality of students, stimulate their learning interests and create the brand of training base, necessarily guaranteeing the sustainable development of the training base. The connotation construction of training base is not only the urgent demand in policy but also the common trend of the base construction.

\section{Contents of the Connotation Construction}

1) The construction of teaching staff: The construction of teaching staff is the important basis for all the construction and development. Necessarily, keep the stability of the teaching staff, pay attention to the improvement of teachers' quality, and optimize the structure. It can be realized through self-training and the introduction of high-level talents.

2) The construction of material culture: The construction of material culture in the training base is the basis to build the base culture, including the authenticity and the figurativeness of environment.

The authenticity of environment means the practical training equipment is in accordance with the production equipment and fully embodies the characteristics of the enterprise culture. It reflects the intercommunity of training bases of the same specialty, so it is difficult for the environment of training base to become distinctive.

The figurativeness of environment means decorating the image of spaces inside and outside the training base to embody the professional and standard features. The ornament should relate to the specialty and embody the specialty features, with reasonable layout, production criterion and reflecting the characteristics of management.

3) The construction of system: The system of training base refers to the rules and regulations as well as the operation mechanism formulated according to the development need of training base, mainly including the practical teaching system and the base management system. The former is used to 
standardize the training standard, like the assessment criterion and the project standard. The latter is used to standardize the management of training base, like the management of equipment, personnel, environment and operation.

\section{The Mode of Training BASE CONSTRUCtion}

The teaching resources are short in Heihe University because of the expansion of school-running scale and the requirement in transforming to the application oriented university this year. It is effective to make the best of social resources, carry out the school-enterprise cooperation and build the training base outside the school. The Computer and Information Engineering College has been approved the 2015 industry-academy cooperation professional comprehensive reform project, the Industry-academy Cooperation Comprehensive Reform of the Computer Science and Technology Plus the Internet of Things Engineering Specialty by the Ministry of Education. This is the first industryacademy cooperation professional comprehensive reform project of the Ministry of Education acquired by our school, as well as the first substantial industry-academy cooperation project of our school. It will play a good demonstration role in training students' innovation ability and practical ability, improving the comprehensive qualities and actively exploring the ways of training high-level application talents through depending on the school-enterprise cooperation and connecting with enterprise demands and enterprise guidance. Heihe University is located in the border of China and Russia, having profound cooperation accumulation with universities of Russia. It is an effective mode to train the applied, international and integrated talents through making the best of the computer training resources of Russia and building the transnational training base of computer application. It will open new path and provide new idea for the external exchange and cooperation through actively exploring the construction of computer training base carried out by China and Russia jointly.

\section{A. The Analog Simulation Mode}

The analog simulation mode helps the development of students' vocational ability and pays attention to the training of abilities in interpersonal communication and teamwork.

Employ managers of the well-known enterprises outside the school to establish the commission of teaching instruction. The commission is responsible for providing the information of talents training requirements, analyzing the vocational and service ability of students and determining the talents training program.

Build the system of dual identity. Teachers serve as the manager of company and students serve as the employee. Emphasize training students' specialized knowledge and technical competence and exert their principal role.

Integrate the training management with the business management gradually. The application of enterprise management mode to the training management can train students' social adaptation ability and realize the enterprisestyle management through signing the agreement and aiming at the high-quality employment.

\section{B. The Order-education Mode}

The school and the enterprise sign the agreement about talent training. The school enrolls students for the enterprise, and the enterprise is responsible to recommend for the employment of students after graduation. Under this training mode, students are under the management of the school and the enterprise after admission. The school and the enterprise teach some specialized courses respectively. In the teaching process, the school and the enterprise provide training for students flexibly at different stages and separate the traditional school training mode, not only expanding the teaching resources of school but also contributing to the creation of enterprise brand and the acquisition of corresponding economic benefit.

\section{The Specialty Construction Mode}

It is necessary to provide related specialties and formulate the programs of talents training and specialty construction according to the enterprise demand and regularly invite the professionals of enterprises to exchange and discuss. Corresponding specialized courses should be provided according to the changes of industrial structure and enterprise demand. In the specialty construction mode, select and send teachers to train in the enterprise yearly, build the teaching staff and speed up the progress of double-professionally-titled teachers' training, which can effectively cover the shortage of double-professionally-titled teachers. Besides, professional teaching materials meeting the enterprise demand through investigation can be chosen, or professionals in enterprises can be invited to compile the textbooks.

\section{CONCLUSION}

In conclusion, the training system is a huge system project for the computer teaching of universities as well as an important way to promote the overall development of students. Schools can only depend on the features of their own and build the distinctive and up-to-date teaching system, so as to train more high-quality professional talents for the society and the enterprises and promote the better development of students.

\section{REFERENCES}

[1] Zheng Jie. Research on the Undergraduate Talent Training Mode of Urban Planning Specialty in Local Colleges [D], Anhui Jianzhu University, 2012

[2] Cai Wenju. Research on the Training Mode of Practical Ability of Students in the Sports Journalism Major of Beijing Sport University [D], Beijing Sport University, 2010

[3] Wang Shuang. Research on the Learning Behaviors of Private College Students [D], Liaoning Normal University, 2011

[4] Jia Houlin. The Cultural Innovation of Training Base under the Connotation Development Model [J], Jiangsu Education, 2009

[5] Han Xue. Research on the Strategy of China and Russia in Establishing the Training Base of Computer Application [J], Electronics World, 2014 